\title{
Erratum to: New approximations for block sorting
}

\author{
J. Huang ${ }^{1} \cdot$ S. Roy $^{1} \cdot$ A. Asaithambi ${ }^{1}$
}

Published online: 21 January 2017

(c) Springer-Verlag Wien 2017

\section{Erratum to: Netw Model Anal Health Inform \\ Bioinforma (2016) 5:6 \\ DOI 10.1007/s13721-016-0113-x}

Figure 1 of the original article should "credit: Anthony Labarre". The below given Fig. 1 is the "Picture by Anthony Labarre, taken from URL".

Fig. 1 Genome rearrangement. Picture by Anthony Labarre, taken from URL

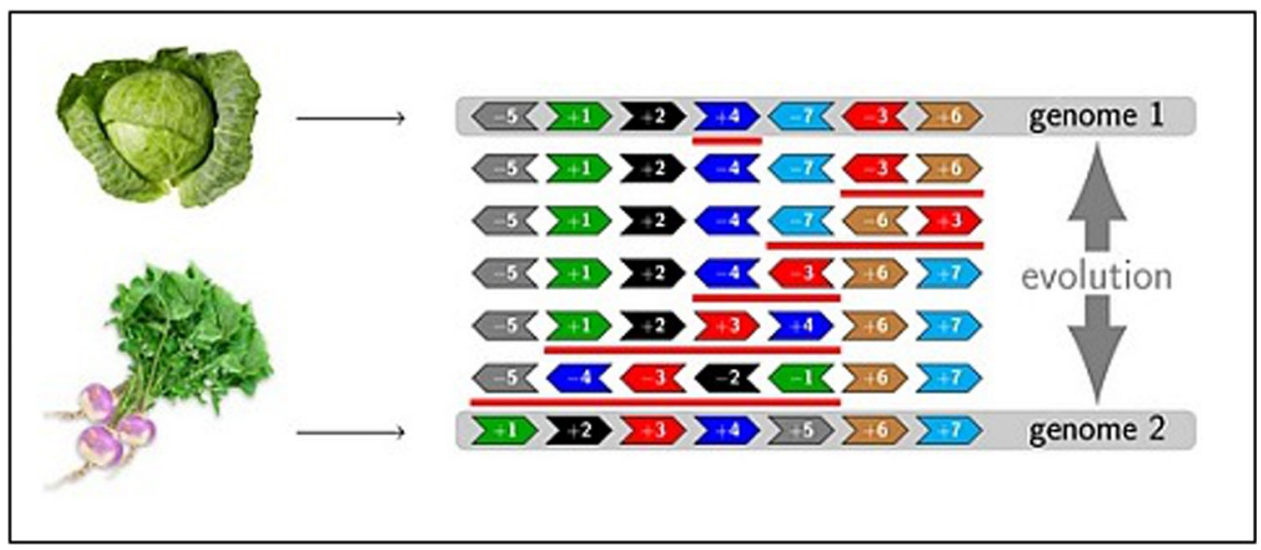

The online version of the original article can be found under doi:10.1007/s13721-016-0113-x.

\section{S. Roy}

s.roy@unf.edu

J. Huang

j.huang@unf.edu

A. Asaithambi

asai.asaithambi@unf.edu

1 University of North Florida, 1 UNF Drive, Jacksonville, FL, USA 